\title{
PROYECTO CALERO: UNA HISTORIA DE MILITARIZACIÓN Y XENOFOBIA ${ }^{1}$
}

\author{
CALERO PROJECT: A HISTORY OF \\ MILITARIZATION AND XENOPHOBIA
}

\author{
Esteban A. Aguilar Ramírez \\ Universidad Nacional de Costa Rica
}

Recibido: 14 de agosto, 2014 • Aceptado: 16 de febrero, 2015

\begin{abstract}
Resumen: El presente trabajo intenta analizar el papel que jugaron los medios de comunicación masiva en relación al conflicto generado entre los gobiernos de Costa Rica y Nicaragua, entorno a Isla Calero. Se discuten los efectos en la opinión pública, el aumento de la Xenofobia en Costa Rica y las relaciones existentes en los procesos de militarización latentes en el país, las cuales se intentaron esconder, justificar o legitimar. Esto incrementó el miedo y el odio generado por este acontecimiento y sirvió de caldo de cultivo para que las voces que cuestionan la "tradición pacífica" de Costa Rica, plantearan la necesidad del restablecimiento del ejército en el país.
\end{abstract}

Palabras clave: Xenofobia, Militarización, medios de comunicación

Abstract: This paper analyzes the role of mass media in the conflict between the governments of Costa Rica and Nicaragua on Isla Calero and its impact on public opinion. The mass media produced a xenophobic attitude and increased militarization in Costa Rica. These effects were minimized, hidden or justified by the government of Costa Rica. Also, the atmosphere created by the media increased fear and hatred among people and generated a debate, proposed by many people, that meant to rethink the "peaceful tradition" of Costa Rica and suggested the need for restoration of the army in the country.

Keywords: Xenophobia, militarization, mass media

1 Este trabajo se inscribe en el proceso de producción del documental Proyecto Calero: una historia de militarización y xenofobia, producido entre octubre del año 2010 y agosto del año 2011. 


\section{Las imágenes ocultas de un conflicto}

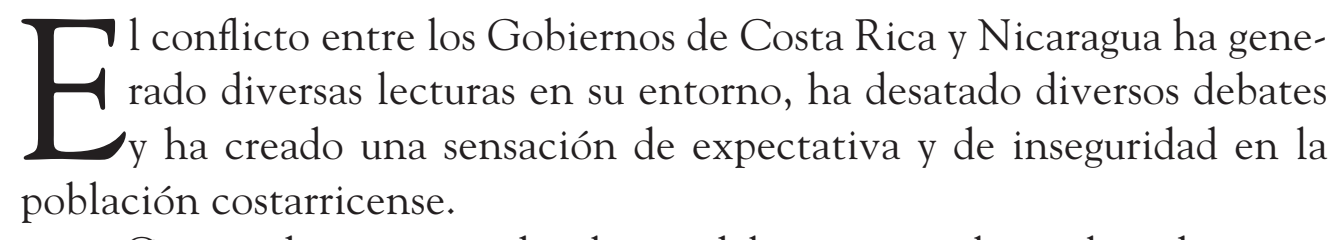

Como es harto conocido, el tema del impacto ambiental que ha generado el dragado ha ocupado las conversaciones de miles de personas alrededor del territorio costarricense, así como la lucha por la soberanía del río San Juan ha generado reacciones similares en el territorio nicaragüense; sin embargo, mi tema de interés se centra principalmente en tres aspectos. En primera instancia, en la influencia de los medios de comunicación en la población costarricense, principalmente en la Gran Área Metropolitana, aspecto que abordo desde tres áreas de la filosofía: la filosofía de la comunicación y, en todo caso, las teorías de la comunicación; la filosofía política -para analizar el papel de los medios de comunicación como actor social e inminentemente como factor político-; y finalmente desde la ética, tratando de realizar un análisis objetivo de su papel, su influencia y su manejo de la información.

Como segundo aspecto, pero no menos importante, se trata el tema de la xenofobia y el nacionalismo, aspectos que, como se verá más adelante, están vinculados. Estos aspectos los visualizo como fruto no solo de un imaginario costarricense inculcado históricamente, sino del conflicto por isla Calero entre ambas naciones centroamericanas. También analizo cómo alrededor de este hecho los índices de xenofobia aumentaron de forma significativa, principalmente incentivados por los medios de comunicación a partir de campañas primordialmente televisivas, sin eximir ningún otro tipo de campaña, ya sea radial o impresa, que exalta los falsos nacionalismos y el odio hacia el «otro», en este caso específico: hacia el nicaragüense.

Este segundo aspecto lo analizo desde una perspectiva ética, desde una ética de la liberación, en contra del odio y de la discriminación del otro, analizando la situación del nicaragüense como migrante, acercándome a un trabajo antropológico de su realidad, en torno al conflicto y a los procesos de discriminación a los cuales ha sido sometido por un porcentaje de la población costarricense. Además de analizar el papel político que juegan los migrantes nicaragüenses no solo en Costa Rica, sino en su propia nación. 
Como un tercer punto, y quizá uno de los más polémicos dentro de esta investigación, se encuentra el tema de la militarización, proceso al que está siendo sometido el pueblo costarricense y que, tomando como excusa conflictos como el suscitado por la isla Calero, busca una mayor aprobación popular. A pesar de estas afirmaciones, los voceros y miembros del Gobierno niegan esta acusación; sin embargo, la dejan plasmada en muchas de sus declaraciones a la prensa nacional e internacional.

El tema de la militarización se aborda desde distintas perspectivas, tomando en cuenta la vasta teoría al respecto sobre los procesos de militarización y la teoría militar que puede aplicarse a este conflicto, así como los análisis requeridos desde la filosofía política que aporten una mayor claridad a esta investigación.

A lo largo de este artículo demuestro cómo se da un triada entre estos tres aspectos, generándose uno al otro, y cuyos gestores detrás de este conflicto mueven a su propia conveniencia, produciendo una exaltación popular tal que la identificación de la población civil con las políticas de Gobierno es cada vez mayor, al menos en lo que respecta al manejo del conflicto con Nicaragua. Esto genera la unidad nacional en contra de un enemigo común, una amenaza que pone en jaque la soberanía costarricense y que, como lo manifestó el canciller de la República René Castro, «está obligando a considerar posturas históricas nuestras» (Castro, 2011), relativas a la supuesta tradición pacifista que ha mantenido el país los últimos años, desde la abolición del ejército hace más de sesenta años.

Además, como un punto adicional dentro de esta investigación, se incluye un breve análisis de la situación de los pueblos fronterizos, principalmente de la frontera norte costarricense. A pesar de que no se tenía contemplado este aspecto dentro del trabajo, es absolutamente necesario abordarlo debido a la delicada situación en la que se encuentran estás poblaciones, principalmente por el abandono en el que habitan. El Gobierno costarricense es indiferente ante esta situación, o al menos lo fue antes del conflicto con el Gobierno de Nicaragua y no se cree que cambie en mayor medida luego de que este conflicto se dé por concluido.

Para iniciar con el análisis relativo a estos aspectos se deben aclarar diversos conceptos, para que la lectura de este trabajo no presente 
ambigüedades, ni se quiera entender un concepto de una manera distinta a la que se plantea en este artículo.

Uno de los primeros conceptos que me interesa dejar claro es el de medios de comunicación:

Como consecuencia del desarrollo y crecimiento de los grandes conglomerados de la comunicación, los medios actuales difícilmente se conciben en el esquema tradicional de espacio público, sino que se definen como espacios privados susceptibles a influir en la política, gestión Estatal y en la vida privada de los individuos (Pla, 2001, p. 1).

Como he manifestado anteriormente, la influencia de los medios de comunicación es innegable dentro de nuestra sociedad, sin embargo, existen algunas posturas que afirman que la participación de las audiencias es vital en la interpretación de la información, sobretodo por los elementos culturales de su entorno, tal y como lo manifiesta David Morley o Stuart Hall.

Al respecto, Héctor Zanella Figueroa, citando a Kappler (1960), mencionó que «las comunicaciones de masas no constituyen normalmente causa necesaria y suficiente de efectos sobre el público, sino que actúan dentro y a través de un conjunto de factores e influencias sociales y del entorno del individuo o de la masa social» (Zanella, 2007, p14).

Sin embargo, mi postura radica en que los medios de comunicación responden a diversos intereses, los cuales definen y afirman a través del abordaje que le dan a la información, tal como lo manifestó Bernardo Sorj:

No se puede desconocer la existencia de grandes grupos empresariales que controlan importantes medios, y que frecuentemente, poseen una amplia gama de ellos. La línea editorial de estos grupos de medios de comunicación ciertamente no es ideológicamente neutra ni deja de tomar en cuenta sus propios intereses empresariales (2010, p. 7).

Estos intereses empresariales responden a una lógica de mercado, a la oferta y la demanda, y los medios de comunicación están sujetos a estos intereses y deben atraer la atención de sus consumidores dentro de un mercado competitivo; «para los medios de comunicación se trata de la lucha por el rating. En este sentido, deben acompañar y satisfacer las preferencias 
del público» (Sorj, 2010, p. 7). Dentro de esta lucha por el rating los medios de comunicación se valen de la noticia, como un reality show; los conflictos entre naciones, como el caso de la querella entre los Gobiernos de Costa Rica y Nicaragua, son «un producto que vende», la noticia se transforma en la mercancía mediante la cual los medios de comunicación subsisten dentro de la agresividad del mercado.

Así lo manifestó la periodista Issa Luna Pla, al afirmar que

La estructura de los medios se encuentra basada en lo que se ha llamado el modelo de mercados, donde el fin último son las ganancias económicas y la ley de la oferta y la demanda mueve las tendencias en cuanto a contenido, variedad de programación y producción, así como importación y exportación de productos mediáticos (Pla, 2001, p. 2).

Estos aspectos de mercado y lucha por el rating se ven agravados cuando los medios de comunicación, en pos de sus intereses y asociaciones políticas e ideológicas, y conscientes del alto nivel de influencia que pueden generar en la población, manipulan la información y, a su vez, la opinión pública respecto a diversos temas: «Dentro de muchos círculos de la sociedad los medios de comunicación han sido tradicionalmente catalogados como un tipo de industria particular en cuanto a su poderosa influencia y manipulación sobre la audiencia» (Pla, 2001, p. 2).

La manipulación debe entenderse como

El propósito de guiar a un público hacia la adopción de conductas y actitudes predeterminadas. Es una resultante de la operación por medio de la cual se orientan y cambian las opiniones, creencias o comportamientos de los públicos, a través de un dirigente político o social o de la influencia de un medio masivo de comunicación. A su vez la principal característica de este efecto consiste en que las personas no son conscientes de su manipulación (Zanella, 2007, p. 15).

Incluso algunos manejan posturas más críticas respecto a la manipulación que ejercen los medios de comunicación sobre la población, y más aún cuando los intereses de los medios van de la mano con el fomento y la legitimación de las políticas del Gobierno. Pascual Serrano, por ejemplo, 
afirmó que «es indiscutible que los medios son instrumentos de propaganda y manipulación, de mayor envergadura, cuando más desarrollado está el sistema mediático de un país o una región» (2009, p. 30), y fue más allá al afirmar que «nadie puede negar que atender diligentemente los requerimientos de un gobierno puede ser muy rentable para un grupo empresarial de comunicación; pues ello le reporta publicidad institucional, legislación beneficiosa, licencias de emisión, mejor régimen fiscal, contratos para otras empresas de holding, etc.» (Serrano, 2009, p. 30). Esta relación entre los medios de comunicación y el Gobierno es un aspecto que trataré más adelante.

Antes de pasar a otro tema, es importante rescatar el papel del periodista dentro de toda esta amalgama de intereses en la que se encuentran inmersos los medios de comunicación, amalgama de la cual el periodista no puede escapar, ya que se ve inmerso dentro de los propios intereses de la empresa para la que labora. No está de más acotar que existen grupos de periodistas que no pregonan los intereses e ideologías de la empresa para la que trabajan, sin embargo, existe un grupo bastante significativo de profesionales en este campo que, a pesar de estar consciente de los daños que puede generar, continúa ejerciendo este tipo de periodismo, ya sea por cinismo o por necesidad. Respecto a este punto, Issa Luna Pla manifestó que

Si antes el profesional producía bajo la influencia del poder Estatal, ahora se adecua a las políticas comerciales e institucionales que la empresa en la que labora le exige, ya sea en favor de un grupo comercial o de un círculo político. Lo cierto es que el periodista, hoy por hoy, no tiene garantizada la libertad de expresión que inspiró a los constituyentes liberales ni a los defensores de los derechos humanos, sino una libertad acotada al abanico de la oferta y la demanda (Pla, 2001, p. 2).

Por otro lado, otro concepto sobre el cual trabajo y es conveniente dejar claro es el de xenofobia: «La xenofobia es una situación donde los habitantes de un país muestran con actos, opiniones y actitudes odio, repugnancia u hostilidad hacia los extranjeros» (Real Academia Española, 1992, citada por Solís, 2009, p. 91), fenómeno altamente marcado en la sociedad costarricense, principalmente dirigido hacia los migrantes nicaragüenses, a los cuales se les acusa de los crímenes, asaltos, problemas de seguridad social y demás males que aquejan a la sociedad costarricense actual y de los que no escapa 
la realidad de la mayoría de los países del orbe. Sin embargo, el costarricense culpa de todos estos problemas a los nicaragüenses que habitan en el país, impulsados en muchas ocasiones por la criminalización de esta población que generan los medios de comunicación, «la comunidad nicaragüense en Costa Rica es frecuentemente racializada y criminalizada» (Sandoval, 2002, p. 2). Para Pedro J. Solís, la xenofobia debe entenderse como un fenómeno histórico:

Como fenómeno histórico que es, la xenofobia no es estática sino que se desarrolla en diversos niveles y logra, en algunos casos, expandirse a toda la población de un país. Por expresar una relación de desigualdad social, la xenofobia implica necesariamente personas o grupos que la reproducen y personas o grupos que la sufren (Solís, 2009, p. 91).

Estos grupos que sufren esta discriminación son descalificados por parte de la población oriunda del país hacia donde han migrado (en este caso concreto, los nicaragüenses en Costa Rica), con la complicidad de los medios de comunicación (campañas nacionalistas) y en muchos casos, por no decir en todos, con la colaboración y bajo el interés del Gobierno nacional (leyes migratorias).

Esta población discriminada (entendiendo por discriminación el acto de separar grupos de personas, a partir de un criterio o criterios determinados; es una manera de ordenar y clasificar en cualquier ámbito utilizando cualquier criterio, ya sea nacionalidad, preferencia sexual, religión, entre otros) no solo es descalificada, es deshumanizada, o sea, se le niega cualquier característica de humanidad, que a su vez la hace un objeto carente de derechos, es monstrificada, se transforma en un elemento ajeno a nosotros, es peligrosa y nociva, es un monstruo que nos puede hacer daño, de tal forma lo expresó Oscar Navarro en el prólogo de la obra de Minor Mora Los Monstruos y la Alteridad: «El monstruo como arma correctora y ejemplificadora de los castigos que sufrirán todos aquellos seres humanos que rompen con los cánones de la normalidad ha sido y es el arma por excelencia de la xenofobia y el odio» (Mora, 2007, p. 8). 
Como mencionaba anteriormente, en el caso de Costa Rica se tiende a achacarles a los migrantes la mayor cantidad de los problemas del país. Citando de nuevo a Pedro J. Solís:

En el caso de Costa Rica, la xenofobia puede explicarse psicológicamente, por medio de lo que Freud denominó narcisismo por la mínima diferencia; económicamente, por la situación económica de la región y la percepción que tienen los costarricenses de que los extranjeros vienen a explotar sus recursos, saturar los servicios públicos y acaparar los empleos disponibles; por razones de contacto, debido a la superioridad que tienden a manifestar los costarricenses en el trato cotidiano con los extranjeros; e históricamente, por cuanto Costa Rica se ha caracterizado por un imaginario etnocéntrico que ha acompañado su formación como Estado-nación independiente (2009, p. 92).

Además, «la discriminación que sufren algunos extranjeros, principalmente los nicaragüenses, se justifica acusándolos de que vienen a desestabilizar social y económicamente al país. Estas justificaciones son formuladas principalmente por aquellos que detentan el poder» (Solís, 2009, p. 94); un claro ejemplo de esta situación se puede encontrar en la Ley General de Migración y Extranjería, aprobada en el 2005, ley que hace ver al Estado costarricense como un Estado xenófobo, que incluso atenta contra los derechos humanos. En esta ley se expone que el Estado no solo puede seleccionar quién ingresa o no al país, sino quiénes en una condición de trabajadores deben someterse a que el Estado considere si son o no de utilidad para el país, negándole el derecho al trabajo al migrante pobre, y solicitando que para poder estar de manera permanente en el país se debe tener un salario que va de los $\$ 600$ a los $\$ 2000$ dólares.

El artículo 76 señala que los extranjeros únicamente pueden ejercer una ocupación previo estudio técnico del Ministerio de Trabajo, pero no se les garantiza si gozarán de las mismas posibilidades y libertades ocupacionales que los costarricenses. En los artículos 77 y 79 se exige que los extranjeros que quieran legalizar su condición en el país deben tener unos ingresos estables. Ciertamente, estos ingresos están por encima del salario mínimo, pues van de los $\$ 600$ hasta los $\$ 2000$ mensuales. 
El artículo 76 señala que los extranjeros únicamente pueden ejercer una ocupación previo estudio técnico del Ministerio de Trabajo, pero no se les garantiza si gozarán de las mismas posibilidades y libertades ocupacionales que los costarricenses. En los artículos 77 y 79 se exige que los extranjeros que quieran legalizar su condición en el país deben tener unos ingresos estables. Ciertamente, estos ingresos están por encima del salario mínimo, pues van de los $\$ 600$ hasta los $\$ 2000$ mensuales. Esto evidentemente excluye a aquellas personas de muy escasos ingresos que vienen al país para mejorar en cierta medida su pobre condición originada en su país natal (Solís, 2009, p. 94).

Esta situación se ve reflejada en las declaraciones del ex diputado Ricardo Toledo sobre la inmigración en un debate parlamentario, acta n. ${ }^{\circ}$ 13, 20 de julio de 2005, para aprobar la actual Ley General de Migración y Extranjería, expediente n. ${ }^{\circ}$ 14.269, que rescató Pedro J. Solís en un artículo acerca de la xenofobia en Costa Rica:

Pero qué diferente es lo que está pasando en nuestra Costa Rica (... un país que ha colapsado el sistema educativo, con más de 7.000 millones de colones que cuesta atender a indocumentados (...) y cuando vemos que cuesta 11.000 millones a la Caja Costarricense de Seguro Social atender indocumentados, dinero que pudo invertirse en mejoras de la Caja, en mejoras del sistema educativo, para que las y los costarricenses tengan mejores servicios, que algunas se atrevan a decir que esta Ley va en contra de los derechos humanos, esta es la peor falacia que yo he oído ¡Y los derechos humanos de los costarricenses! (Solís, 2009, p. 94).

En una ley de este tipo, con un corte prácticamente fascista, se puede encontrar cómo la discriminación por origen nacional es avalada incluso legalmente; además, la Declaración de las Naciones Unidas sobre la eliminación de todas las formas de discriminación racial (1963) dicta sobre estos aspectos de discriminación racial en el inciso 2 del artículo 2 que «ningún Estado fomentará, propugnará o apoyará, con medidas policíacas o de cualquier otra manera, ninguna discriminación fundada en la raza, el color o el origen étnico, practicada por cualquier grupo, institución o individuo» (Asamblea General de las Naciones Unidas, 1963). Esto deja muy claro que la bandera que levanta con orgullo el Gobierno costarricense, de ser un Estado defensor de los derechos humanos, queda en entredicho. 
Aunado a la xenofobia trabajo el concepto de nacionalismo. Por nacionalismo se pueden entender distintas afirmaciones, sin embargo, me baso principalmente en dos: el nacionalismo como la identificación de un individuo con la nación propia, vinculado a un sentido doctrinal o una acción política concreta, y, por otro lado, el nacionalismo como doctrina política, que se puede entender «como aquella doctrina política que sostiene que la titularidad última de la soberanía reside en la nación» (Rodríguez, 2006, p. 3). De esta manera, la presente investigación se basa en dos conceptos de nacionalismo relacionados con la perspectiva de la identificación nacional y la perspectiva de la soberanía.

Sin embargo, no se puede continuar con la idea del nacionalismo sin aclarar qué se entiende por nación y de esta manera poder hablar acerca de la identificación del individuo con esta. Para Hans Morguenthau, «la nación es una abstracción conformada por un conjunto de individuos que tienen ciertas características en común y son esas características, precisamente, las que los convierten en miembros de la misma nación» (1986, p. 133), sin embargo, «la pertenencia a una nación puede definirse en términos de lenguaje, cultura, origen común, raza o por la decisión de los individuos de pertenecer a una nación» (Morguenthau, 1986, p. 201).

Con base en este sentimiento de pertenencia a una nación, ya sea por cualquiera de las razones mencionadas anteriormente, se suscita la identificación del individuo con esta, sin embargo, Morguenthau afirmó que «la identificación con la nación cumple un doble propósito de satisfacer ambiciones personales de poder y aliviar los temores individuales proyectándolos al plano internacional» (1986, p. 141); de la misma manera este autor señaló que

Esta identificación, cada vez más intensa y completa, es la fuente de la ferocidad y la rudeza de las políticas internacionales modernas, que representan un entrechocar de ambiciones apoyadas por virtualmente la totalidad de las poblaciones con una dedicación y emoción sin precedentes, que en anteriores períodos históricos solo fue patrimonio de algunas religiones (Morguenthau, 1986, p. 142).

Este referente teórico se puede ver reflejado en acciones recientes, como el caso del conflicto que analizo en esta investigación. La identificación 
del pueblo costarricense con la política exterior del país en torno al manejo del conflicto con Nicaragua superó cualquier afinidad de la población con el Gobierno durante los últimos años, la opinión popular validó las acciones tomadas por el Gobierno, desembocando en nacionalismos extremos y elevando de esta manera los niveles de xenofobia en el país.

Morguenthau afirmó que

El poder encubierto tras las ideologías y perseguido en nombre y en beneficio de la nación se transforma en un bien que todos los ciudadanos deben procurar. Los símbolos nacionales, especialmente si hacen referencia a las fuerzas armadas y a las relaciones con otras naciones, son instrumentos de esa identificación de los individuos con el poder de la nación. La ética y las costumbres de la sociedad tienden a hacer atractiva esa identificación al dispensar recompensas y amenazar con castigos (1986, p. 135).

Así se puede ver cómo la identificación con la nación no solo es una muestra de nacionalismo, sino de que la carencia de esta puede ser castigada e incluso catalogada de traición; para continuar con las analogías entre esta teoría y el conflicto entre los Gobiernos de Costa Rica y Nicaragua, principalmente en la manera en la que se vivió el conflicto en nuestro país, cabe citar las declaraciones de la presidenta de la República Laura Chinchilla, quien habló de diversas medidas a tomar en la frontera con Nicaragua, como reforzar la vigilancia, bloquear y regular la navegación sobre el río Colorado y evitar el trasiego de alimentos y combustible para los nicaragüenses. «Estas medidas drásticas les dificultan a ellos el trabajo en la zona. Además he instruido para que se busquen las figuras penales respectivas, porque no puede haber traición a la patria» (Cambronero, 2010, p. 4); en declaraciones como esta se puede ver que la falta de esta identificación con la nación y su política exterior debe ser castigada, además se puede unir a estas posiciones los llamamientos de la prensa en pos de la causa nacionalista, como el que se muestra a continuación: «Ningún costarricense puede ser indiferente ante la ocupación militar de nuestro territorio, no importa cuán pequeña sea la porción de tierra invadida» (Editorial de La Nación, 16 de noviembre de 2010, p. 29A).

Estos son solo dos ejemplos de las relaciones que se pueden establecer entre las teorías que se han estudiado y la situación en torno al conflicto de interés, sin embargo, será en otro apartado donde se ahondará al respecto. 
Ahora bien, continuando con los conceptos que se deben aclarar antes de adentrarse en el tema de la investigación, el concepto de soberanía, según Nicola Matteucci y Norberto Bobbio en su Diccionario de Política,

Se refiere al uso del poder de mando o del control político que se ejerce en distintas formas de asociación humana y que implica la existencia de algún tipo de gobierno independiente que se apoya en la racionalización jurídica del poder. La soberanía incorpora la noción de legitimidad en oposición al uso arbitrario del poder por parte de los actores que se amparan en la fuerza y en la coerción para imponerse sobre los demás. Implica entonces la transformación de la fuerza en poder legítimo. El paso del poder de hecho al poder de derecho (Matteucci, 1982).

Sin embargo, dentro de la investigación esta definición no es del todo satisfactoria. Es necesario enfocarse en lo que se entiende por soberanía nacional, que es un concepto ideológico que surgió de la teoría política liberal a finales del siglo XVII en Inglaterra y en el siglo XVIII en Francia, en la cual se plantea que la soberanía pertenece a la Nación, una entidad abstracta y única vinculada a un espacio físico al que pertenecen todos los ciudadanos y se define como superior a los individuos que la componen.

Por otro lado, la soberanía territorial es la que consiste en que el Estado ejerza una «autoridad suprema dentro de un territorio determinado, que incluye las aguas territoriales y el espacio aéreo correspondientes a los límites geográficos del país» (Márquez Rodríguez, 2005), lo cual implica que en virtud del concepto de soberanía ningún Gobierno extranjero puede intervenir en los asuntos de otro país, «así como también el del respeto a la llamada libre determinación de los pueblos, según la cual el pueblo de un país puede darse la forma de gobierno y alinearse ideológicamente como quiera, en forma absolutamente libre» (Márquez Rodríguez, 2005), y respecto a la soberanía territorial, «ningún país puede pretender aplicar su legislación ni ejercer autoridad alguna en el territorio de otro, ni siquiera sobre sus propios ciudadanos que se encuentren transitoria o permanentemente en dicho territorio, sea cual fuere la situación en que se hallasen» (Márquez Rodríguez, 2005).

Ahora bien, valiéndose de estos tres conceptos referentes a la soberanía se puede tener más claro a qué se refiere el Gobierno costarricense cuando asevera que Nicaragua ha invadido su territorio y socavado la soberanía, 
tildando el hecho como «una grave violación a nuestra soberanía» (Arroyo, 4 de noviembre, 2010, p. 2), según también las palabras de la presidenta Laura Chinchilla y que los medios de comunicación han reafirmado asegurando que «se trata de una invasión militar contra el suelo costarricense y no de una discusión o divergencias sobre asuntos fronterizos o de otra índole» (Editorial de La Nación, 6 de noviembre de 2010, p. 32A).

Otros de los conceptos vitales dentro de este trabajo son la militarización y el militarismo. Por militarismo se puede entender «la concepción que supone que el poder de una nación consiste, primaria y exclusivamente, en la fuerza militar que posea, concebida especialmente en términos cuantitativos» (Morguenthau, 1986, p. 203). Con base en este concepto se puede empezar a analizar las críticas que se le hacen al Gobierno costarricense respecto a las políticas de seguridad que ha implementado en torno al conflicto con Nicaragua; este «anuncio del gobierno de crear y "armar un cuerpo de seguridad" (...) no es otra cosa que un primer paso hacia el militarismo» (París, 20 de enero, 2011, p. 28A). «La invasión de tropas nicaragüenses a nuestro territorio ha producido (...) una actitud favorable de muchos costarricenses para crear una fuerza armada, aunque eufemísticamente se le llame "policía de frontera" o "cuerpo de seguridad", que conlleva un renacer de ese espíritu bélico (...)» (París, 2011, p. 28A), y amparándose en la figura de la invasión nicaragüense a isla Calero justifica dichas acciones.

Por otro lado, el concepto de militarización es quizá un concepto más adecuado para los fines investigativos de este trabajo. Brian González mencionó que, según el diccionario de la Real Academia Española, por militarización se entiende el acto de «inculcar o infundir una disciplina militar, organizar una colectividad en una esencia militar» (González, 2011), o sea, el proceso de militarización no corresponde precisamente a observar tanques o soldados en la calle, o a observar militares realizando sus ejercicios, «tiene que ver más con un discurso» (González, 2011), un discurso que trata de inculcar esta disciplina militar. En el caso de Costa Rica se puede percibir estas características dentro del discurso que se ha manejado en torno al conflicto con Nicaragua. Brian González mencionó, por ejemplo,

Lo que decía Tijerino de reactivar las defensas aéreas, o antiaéreas, el entrenamiento que van a recibir los policías, además es interesante como ya 
no se utiliza el concepto de policía, para referirse a la policía, se habla de fuerza pública (...) si nos remitimos al diccionario fuerza sería un sinónimo de ejército, y además que es el ejército, el ejército se mantiene con el gasto público, es decir es un fuerza pública (González, 2011).

Dentro de estas mismas nociones, cabe referirse al concepto de invasión, tan utilizado al hacer referencia a la situación que se está viviendo entre los Gobiernos de Costa Rica y Nicaragua; por invasión se entiende algo que «tiene que ver más con una ocupación de gran magnitud» (González, 2011), por ejemplo 7000 marines y 46 buques de guerra, «eso sí sería invasión» (González, 2011), en cambio a «una ocupación por unos pocos soldados se le llama escaramuza, que sería una ocupación de poca importancia» (González, 2011), que sería lo que realmente sucede en la frontera norte del país. Sin embargo, la intencionalidad de utilizar un término como este, invasión, remite directamente a una agresión y busca exaltar el nacionalismo costarricense para que se levante en defensa de la soberanía nacional; de esta forma, el discurso del Gobierno (contando con el apoyo de los medios de comunicación) logra su objetivo de inculcar esa esencia militar a la que responde el proceso de militarización que está viviendo el país.

Un concepto que es preciso analizar es el de guerra. Para Clausewitz «la guerra es un acto de fuerza para imponer nuestra voluntad al adversario» (Von Clausewitz, 2003, p. 18), además «la guerra no es sólo un acto político, sino un instrumento político real, una extensión de la actividad política, una perpetración de la misma por otros medios» (Von Clausewitz, 2003, p. 41), en otras palabras «la guerra es la extensión de la política por otros medios» (Von Clausewitz, 2003, p. 41). Sin embargo, este concepto de guerra, que data de inicios del 1800, Foucault lo invirtió al afirmar que «la política es la guerra continuada con otros medios» (1998, p. 24), haciendo referencia a las relaciones de poder que funcionan en nuestra sociedad, donde

Se injertan esencialmente en una relación de fuerzas establecidas en un determinado momento, históricamente precisable, de la guerra. Y si es verdad que el poder político detiene la guerra, hace reinar o intenta hacer reinar una paz en la sociedad civil, no es para suspender los efectos de la guerra o para neutralizar el desequilibrio que se manifestó en la batalla final. El poder político, en esta hipótesis, tiene de hecho el papel de inscribir perpetuamente, 
a través de una especie de guerra silenciosa, la relación de los cuerpos de unos y otros (Foucault, 1998, p. 24).

Además, para Foucault, «dentro de la paz civil, o sea en un sistema político, las luchas políticas, los enfrentamientos relativos al poder, con el poder, para el poder, las modificaciones de las relaciones de fuerza deberían ser interpretados sólo como la continuación de la guerra» (1998, p.24); el ejercicio del poder es una guerra continua, según Foucault, y la política es una lucha por el poder, o sea, otra acción más dentro de la guerra.

Por otro lado, dentro del concepto de guerra existen distintas variables que quizá no viene al caso analizar por completo, pero es necesario hacer referencia a ellas, por ejemplo, el caso de la guerra preventiva, que es la guerra que inicia una nación ante la supuesta amenaza de ser atacada por otra nación; la guerra civil, que es la que se suscita entre los habitantes de un mismo pueblo o país; la guerra santa, que es la promovida por motivos religiosos; la guerra sucia, que es la que se da fuera de los marcos legales; la guerra fría, que es la que intenta socavar los regímenes políticos enemigos; y la guerra mundial, que hace referencia a un conflicto bélico donde actúan o participan distintos países y distintos continentes. Relacionada con estos conceptos se encuentra la noción de defensa nacional, que sería todas las actividades políticas que realiza un país o una nación para evitar o rechazar ataques militares de otros países, principalmente resguardando sus fronteras, para evitar agresiones o invasiones por parte de naciones enemigas.

Ahora bien, para terminar con los conceptos, se hace referencia a dos términos importantes dentro de esta investigación: el concepto de ética de la liberación y el de filosofía política. Por ética de la liberación, término acuñado por Enrique Dussel, se va a entender lo siguiente: «La Ética de la Liberación, no pretende ser una filosofía critica, se trata de una ética cotidiana, desde y a favor de las inmensas mayorías de la humanidad excluidas de la globalización» (Dussel, 1998, p. 15). Así, a partir de una ética de este tipo, que contemple y visibilice a los históricamente excluidos, se puede analizar de una manera más clara el papel y la situación de los grupos de inmigrantes nicaragüenses en Costa Rica, principalmente su situación a partir del conflicto entre ambos Gobiernos centroamericanos. 
Por último, por filosofía política se va a entender a una rama de la filosofía que estudia aspectos fundamentales acerca del Gobierno, la política, la libertad, la justicia, la propiedad y los derechos, por lo cual es una herramienta completamente válida y necesaria para el análisis del conflicto que ocupa esta investigación.

\section{El papel de los medios de comunicación}

Los medios de comunicación han jugado un papel muy importante dentro del panorama sociopolítico actual, a lo largo y ancho del orbe, y Costa Rica no es la excepción, la influencia de los medios de comunicación dentro de los problemas y acontecimientos que se han desarrollado en el país a lo largo de los últimos años es palpable y se refleja en la posición que asume la opinión pública respecto a estos acontecimientos.

Como ya se ha mencionado, el papel que han jugado los medios de comunicación en torno al conflicto entre los Gobiernos de Costa Rica y Nicaragua respecto a isla Calero ha sido muy importante dentro del desarrollo del mismo, en suma con las reacciones que ha generado en la población mediante el uso de la información que producen los medios escritos, televisivos y radiales.

Casos concretos como las campañas televisivas de la cadena Repretel y las radiales de Central de Radios han despertado un nacionalismo banderil que ha incrementado aún más los niveles de xenofobia característicos de este país. Así lo manifestó la periodista costarricense Andrea Aguilar en un artículo publicado en la prensa nacional:

Exaltar un nacionalismo banderil, como lo han hecho ciertos medios de comunicación, formadores de opinión que han perdido la conciencia de que vivimos en un país con una xenofobia tan solapada (...) Ese pseudo-nacionalismo, en un país donde cantar el himno a las seis de la tarde ha sido considerado una polada por décadas, es la llama que se ocupa para que el menosprecio (ó digámoslo con todas las letras O-D-I-O) entre países siga ardiendo con más fuerza (2010, p. 31A).

Sin embargo, surge la incógnita acerca de qué ganan los medios de comunicación alentando el odio entre las naciones, e incluso siendo partícipes 
del inicio de un conflicto bélico ¿Qué ganan los medios de comunicación apoyando la guerra?, sería la principal incógnita. Según Pascual Serrano, «existe otra responsabilidad de los medios, quizás más infame todavía, y es que el espectáculo de la violencia vende» (Serrano, 2009, p. 31). Se puede ver claramente este aspecto dentro del conflicto entre estas dos naciones, donde los medios de comunicación, en una lucha descarnada por el rating, vendían la noticia de isla Calero como un verdadero reality show, se «adentraban» en la zona del conflicto y nos hacían llegar imágenes que prácticamente vaticinaban una guerra, o al menos un conflicto de baja intensidad de manera inminente. El mismo Pascual Serrano, citando a la socióloga Ángeles Díez (2007), escribió:

Los medios de comunicación forman parte del selecto club de los beneficiarios de las guerras en un doble sentido: a) por la posibilidad de la elaboración de mercancías (las noticias de guerra) con gran potencial de audiencia, por tanto como potencialidad económica, b) por la reafirmación de su poder como creadores de opinión pública, es decir, como agentes privilegiados de la construcción del consenso, potencial que puede reportarles pingües beneficios directos e indirectos (Serrano, 2009, p. 31).

Los medios de comunicación generan «un estado de opinión entre la ciudadanía que siente las bases adecuadas de odio y agresividad necesarias para iniciar la confrontación» (Serrano, 2009, p. 33), y esto es más que claro al referirse a las campañas de Repretel y Central de Radios que mencionaba anteriormente, las cuales -con la frase «exigimos respeto» y los llamamientos a exaltar el nacionalismo, a «sacar la bandera» y hacernos respetar- despertaron estos odios, que incluso en diversos sitios de Internet, tal como Facebook, se hicieron sentir con gran fuerza:

Una revisión de EL NUEVO DIARIO a redes sociales como Facebook, Twitter y otros foros locales de dominio costarricense, así como denuncias interpuestas en nuestra página web de diferentes partes del vecino país del norte, comprobó que la crisis diplomática entre ambos países desató esos sentimientos, a tales extremos que algunos grupos llaman a tomar las armas «para exterminar a esa plaga», en referencia a los trabajadores nicas al otro lado de la frontera (Silva, 2010). 
Incluso se pueden encontrar afirmaciones en medios de prensa escritos que incentivan el nacionalismo, el rencor y la sensación de estar siendo agredidos, invadidos y a las puertas de un conflicto de mayor intensidad: «Decenas de sus militares permanecen en suelo nacional, violentando la soberanía costarricense» (Editorial de La República, 2010, p. 14), además, haciendo un llamado a la defensa del país y a la agresión hacia Nicaragua, insinuando la amenaza que es ese país. Dentro de la misma nota se afirma que «Costa Rica debe invocar al consejo de seguridad lo antes posible para detener la invasión nica» (2010, p. 14), haciendo ver que la situación podría agravarse en perjuicio de Costa Rica, utilizando, al igual que todos los medios de comunicación, el término invasión, que, como se vio anteriormente, no se apega realmente a lo que acontecía en la frontera norte del país. Además, la utilización de este tipo de conceptos, también utilizados por el Gobierno, genera una sensación de indefensión en la población, se legitima el discurso militarizante del Gobierno y la sensación, en cierta parte de la población, de que es necesario reinstaurar el ejército en el país. Sobre este aspecto me referiré más adelante.

Por otro lado, otros medios de comunicación publicaban notas de deslegitimación en contra del Gobierno nicaragüense, exaltando la posición del costarricense y el imaginario identitario que maneja la mayor parte de la población nacional, como país pacífico, solidario y respetuoso de los derechos humanos:

La posición de Costa Rica ha sido firme y transparente y su estrategia se circunscribe a los hechos, a la verdad, a nuestras tradiciones y a la buena fe, todo sustentado en el apoyo y en las convicciones de nuestro pueblo. Por ello nuestra actitud es concreta y comprensible, al contrario de la posición de Ortega y su Gobierno conformada por un amasijo de mentiras, contradicciones, invenciones, falacias y exabruptos que, han desacreditado aún más al régimen de Ortega y ofendido la dignidad del pueblo nicaragüense (Editorial de La Nación, 6 de noviembre de 2010, p. 32A).

Además de aparentar cierta compasión y respeto hacia el pueblo nicaragüense, en lo que se podría denominar una estrategia para evitar algún tipo de inconveniente con la población radicada en Costa Rica, este discurso se aprovecha de la polarización política existente en esa nación. Y aún más, 
se afirman como dueños de la verdad negando cuanta opción o resabio de duda exista, afirmando que

Ha quedado al descubierto la soledad de Daniel Ortega en Nicaragua y en el exterior, al mismo tiempo que ha resplandecido la razón en la posición expuesta por la presidenta de Costa Rica, Laura Chinchilla, quién, con la fuerza que le confieren la verdad y el derecho, exige el retiro de los efectivos del Ejército de Nicaragua del territorio nacional. «En la serenidad - que confiere la verdad esta nuestra confianza», decíamos en nuestra editorial del 3 de noviembre pasado (Editorial de La Nación, 9 de diciembre de 2010, p. 34A).

Como se puede ver, el manejo de la información de los medios es una posición parcializada y dista mucho de lo que debe ser una acción periodística objetiva. Pascual Serrano, citando a Roger Buoen (s. f.), miembro ejecutivo del diario Star Tribune, escribió respecto a la labor real de un periodista:

Nuestro trabajo no consiste en valorar a los protagonistas de nuestros artículos, sino en describir sus actos, sus entornos y sus identidades de la manera más completa posible, dejando que los lectores lleguen a sus propias conclusiones sobre los individuos y las organizaciones (Serrano, 2009, p. 28).

«Esos valores absolutos a la hora de valorar un conflicto, no sólo suponen un sesgo informativo, sino que bloquean cualquier salida de diálogo ante el imaginario ciudadano» (Serrano, 2009, p. 29). Asimismo, Serrano afirmó que «tras la guerra en los medios de comunicación empieza la guerra de las armas» (2009, p. 39); tal es el caso de Bosnia, donde

Muchos analistas han afirmado que sin medios de comunicación, concretamente sin televisión, hubiera sido muy difícil que hubiese estallado la guerra en Bosnia. La convivencia de los medios de comunicación con los nacionalismos más extremos (salvo honrosas excepciones), sentaron las bases para el conflicto bélico (Serrano, 2009, p. 37).

Con ejemplos como este se puede entender cómo, a partir de un uso malintencionado de la información por parte de los medios, la verdadera amenaza a la estabilidad y la paz entre los países puede provenir directamente 
de quienes nos están informando, entre ellos también se encuentran las esferas gubernamentales. Como mencioné varias páginas atrás, para nadie son un secreto los beneficios que pueden obtener los medios de comunicación aliándose y beneficiando al Gobierno.

«Para "vender la guerra” el discurso mediático se alinea con el político para tratar de presentar la agresión como una cruzada en defensa de ideales» (Serrano, 2009, p. 62). De nuevo se puede establecer una analogía entre esta afirmación y las campañas de la cadena Repretel y de Central de Radios en defensa de la soberanía nacional: «La apelación al patriotismo puede despertar la más miserable de las reacciones humanas, la guerra» (Serrano, 2009, p. 64), además, otro aspecto que se debe analizar y relacionar con el manejo de la información por parte de los medios es el de hacer

La rotunda afirmación previa de que no se desea la guerra, la adjudicación al adversario de la única responsabilidad en la guerra, la demonización del enemigo, el enmascaramiento de los fines reales presentándolos como nobles causas (...) el recurso del apoyo de artistas e intelectuales a la causa (...) la acusación de traidores a quienes ponen en duda la propaganda de guerra (Serrano, 2009, p. 63).

Otro aspecto que no se puede dejar de lado es cómo los medios de comunicación colaboraron, con esta cobertura y con la exaltación del nacionalismo, a mejorar la imagen del Gobierno costarricense a partir de este conflicto, y cómo la popularidad de la presidenta Laura Chinchilla y su equipo de trabajo se vio beneficiada a causa de esta escaramuza, tal como lo presentó la prensa nacional el 26 de noviembre de 2010: «Este conflicto de Costa Rica con Nicaragua disparó las opiniones favorables sobre la labor de la presidenta Chinchilla, su equipo de gobierno e incluso su personalidad» (Oviedo, 2010, p. 5A), además este autor agregó que el «conflicto elevó la imagen de Chinchilla en menos de un mes, según Unimer» (2010, p. 5A), contando con un $66 \%$ de apoyo por parte de la población respecto a su actuar en torno al conflicto; aumentó la popularidad del $41 \%$ al $62 \%$ y las opiniones negativas cayeron del $17 \%$ al $12 \%$; y respecto a su personalidad se incrementaron las opiniones positivas de un $76 \%$ a un $87 \%$. 
Tal como se observa, el papel de los medios de comunicación ha sido muy importante dentro de este conflicto; han generado mayor xenofobia en la población, han despertado nacionalismos vacuos, han entrado en luchas por rating, han legitimado el discurso bélico del Gobierno que se esconde tras la cortina de la paz. Los medios se tratan de camuflar dentro del discurso del odio a la guerra y el rechazo a la violencia. «Las referencias a la paz son constantes en los medios de comunicación. Algunas de ellas no exentas de cinismo» (Serrano, 2009, p. 162). Los medios han generado una sensación de inseguridad en la población.

En fin, son múltiples los efectos que logran generar los medios en situaciones como esta; su relación con la xenofobia y la militarización es clara y marcada, tal como se verá en los siguientes apartados, donde se podrá visualizar la relación entre estos otros aspectos que ocupan un espacio relevante dentro de la investigación, por lo cual no es de extrañar que continúe haciendo referencia al papel de los medios de comunicación.

\section{Xenofobia y nacionalismo}

La xenofobia es un fenómeno que ha estado latente durante muchos años en Costa Rica, siendo afectados, principalmente, los inmigrantes nicaragüenses, quienes representan «más del 70 por 100 de los extranjeros en Costa Rica» (Solís, 2009, p. 93).

Los medios de comunicación han colaborado en gran medida a que esta situación sea así:

La emigración también está siendo utilizada para generar miedos e inseguridades. El resultado es enormemente preocupante, se sientan las bases de la xenofobia y el racismo, se desarrolla el nacionalismo excluyente frente a otros pueblos y naciones y se justifica que las fuerzas de seguridad puedan cometer abusos contra esos colectivos (Serrano, 2009, pp. 120-121).

Y en el caso de Costa Rica:

Los medios de difusión han promovido imágenes que asocian la comunidad nicaragüense con un sentido de «amenaza», especialmente a través de las noticias de sucesos, las cuales constituyen una modalidad periodística sin el 
destaque de las noticias sobre economía o política, pero con una más amplia y diversa audiencia, la cual puede reconocer fácilmente los personajes arquetípicos (por ejemplo, héroes, ayudantes, víctimas o villanos) presentes en las narrativas (Sandoval, 2002, p. 5).

Este fenómeno se ha visto incrementado al calor del conflicto entre ambos Gobiernos, desatando odios y resentimientos, generando miedo hacia el otro, en este caso hacia el nicaragüense, y, tal como lo mencioné con anterioridad, los medios de comunicación han sido un factor determinante para que esto suceda; las redes sociales han sido un filtro para plasmar el odio entre las naciones, para mostrar claramente la xenofobia que carcome a la población. Tal como se manifiesta en la prensa nicaragüense:

Al calor de la disputa binacional entre Costa Rica y Nicaragua, han explotado con una fuerza nunca antes vivida en la sociedad costarricense, una serie de manifestaciones de xenofobia y de discriminación contra nicaragüenses que viven en ambos países centroamericanos, pero sobre todo contra los inmigrantes radicados al sur del Río San Juan (Silva, 2010).

Por su parte, la prensa costarricense también hace mención de este problema: «Las redes sociales en Internet, especialmente facebook, se han convertido en sitios donde ha salido a relucir la xenofobia entre algunos costarricenses y algunos nicaragüenses» (Fonseca, 2010), sin embargo, minimiza la situación y hace ver el problema de la xenofobia como una problemática casi sin importancia.

Empero, existen manifestaciones xenofóbicas altamente preocupantes por parte de «algunos costarricenses», como los llamó la prensa nacional, y que no solo hacen referencia a los inmigrantes nicaragüenses, sino que van más allá, como lo muestra una nota de prensa del país vecino del norte, la cual transcribo casi en su totalidad por la relevancia que tiene y lo alarmante de su contenido: «Otro sitio en esa misma red (haciendo referencia a Facebook), denominado "Costa Rica Army", llamaba en tono de broma a los costarricenses a tomar las armas, a recobrar el Ejército abolido en 1948 y disparar contra "los nicas invasores"»(Silva, 2010).

Otro documento que circuló en blogs, redes y foros de comunidades nacionalistas de Costa Rica fue publicado por el sitio Nuevo Orden, donde 
los autores hablaban de «pureza racial», limpieza étnica y aplicaciones de políticas estilo apartheid a los extranjeros. "Es el deber nacional de los costarricenses extender e incrementar su dominio político y económico sobre Centroamérica. Y pasar de ser la Suiza centroamericana a convertirse en los EE.UU. centroamericanos» (Silva, 2010), enarbolaban los autores del demencial escrito.

Manchas en el tapiz blanco costarricense serían los barrios nicaragüenses en San José, donde los inmigrantes conformaron guettos repletos de corrupción, incesto y muerte. Zonas como La Carpio, el barrio nica más grande del país. Así como otros reductos de inmigrantes nicas en las cuatro provincias urbanas".

"Son manchas étnicas también Guanacaste, provincia del norte, poblada en su mayor parte por mestizos semi indígenas de extracto étnico y cultural idéntico a los nicas. Y Limón, la provincia más pequeña de Costa Rica, donde la mayoría de la población es negra. Y que, casualmente, es la provincia más pobre", reza el texto titulado "El imperio costarricense".

Ahí proponen, entre otras cosas, la restauración del ejército nacional, impedir la inmigración legal ó ilegal

... y deportar a sus países de origen a todos los nicas, colombianos, chinos y demás inmigrantes. Sus bienes serán incautados para cubrir los gastos de deportación.

Aislar totalmente, en forma de un Apartheid cultural y étnico, a los sectores discordantes de la etnia costarricense. Que los negros de todo el país sean recluidos en Limón y mantenidos allí sin que puedan salir del área. Y sacar de Limón a todos los pobladores blancos puros. De igual manera, recluir a los sectores indígenas a sus reservas, y a los casos de mestizaje más severos a Guanacaste, dice el escrito fascista" (Silva, 2010).

Un escrito de este tipo es una muestra alarmante de lo que se está generando en la población, y lo peor es que los medios de comunicación no solo alientan al nacionalismo y por consiguiente a la xenofobia, sino que minimizan esta situación invisibilizando el problema y acentuando el imaginario costarricense de ser un país «pura vida», en donde las manifestaciones 
de odio de este tipo son impensables, porque esas características negativas son propia de los otros (como los nicaragüenses), pero nunca una característica de este tipo podría asociarse con el pueblo costarricense, en todo caso, si alguno se expresara de esta manera sería un «mal tico», que representa a una escasa minoría que no expresa la esencia del «ser costarricense».

Tal como lo manifestó Pedro J. Solís,

La identidad nacional costarricense sin duda, forma parte de un imaginario que está desligado de la realidad política, social y económica del desarrollo nacional. La insistencia en las características de homogeneidad racial, de pureza etnocultural y racionalidad, ésta última característica alentada por filósofos e intelectuales de la segunda mitad del siglo XX (Solís, 2009, p. 95).

Dichas características son las que han marcado la construcción de ese imaginario que los medios de comunicación alientan, gracias a los beneficios que les genera vender la imagen del tico.

En fin, el problema de la xenofobia no es una situación nueva en Costa Rica, a pesar de que se quiere camuflar o negar, en algunos casos incluso la misma presidenta de la República, Laura Chinchilla, negó ante las cámaras de televisión que en Costa Rica existieran manifestaciones xenofóbicas, exaltando las «cualidades pacíficas» del costarricense, que además no se deja llevar por el calor del conflicto para agredir o discriminar a los nicaragüenses que habitan en nuestro país. Declaraciones que distan mucho de la verdad y que cualquiera podría refutar, si así lo quisiera.

Pero ante todo, vuelvo a preguntar ¿por qué incentivar la xenofobia en torno a este conflicto? Lo que arroja la respuesta resulta muy interesante para algunos y fuera de tono y controversial para otros. Pero el interés de incrementar los índices de xenofobia responde a factores políticos bastante delicados. La xenofobia no solo conlleva al odio, sino también al miedo. Como mencioné con anterioridad, la criminalización del nicaragüense por parte de los medios lo han convertido en una amenaza y la sensación de inseguridad respecto a este es cada vez mayor; más aún cuando al nicaragüense ya no solo se le asocia con crímenes, asaltos, asesinatos, violencia doméstica y demás aspectos negativos, sino que ahora se le vincula con la invasión al territorio costarricense, se le ve como una «amenaza militar», se convierte en un enemigo. 
Sin embargo, ante esta construcción del enemigo, existe otro factor, y es que, si el nicaragüense es el «enemigo», el costarricense necesita defenderse y ante la ausencia de una fuerza militar se encuentra indefenso, por lo cual se vuelve necesario que en Costa Rica se reinstaure el ejército o se forme una fuerza militar o «policial» similar, que tenga la capacidad de defender al país de la «amenaza» que representa Nicaragua para la estabilidad y la soberanía nacionales; de esta manera lo manifestó la presidenta Chinchilla al afirmar que «Costa Rica no se ha tomado en serio lo que supuso la abolición del ejército. Hay indefensión» (Solano, 2 de diciembre, 2010, p. 6). Se puede añadir otras declaraciones hechas a la prensa en las que afirmó que «tal y como ha manifestado el señor canciller, no podemos llevar nuestra tradición pacifista a un extremo tal que nos neguemos la necesidad de proteger nuestra soberanía e integridad territorial» (Murillo, 14 de enero de 2011, p. $5 \mathrm{~A}$ ), haciendo referencia a las declaraciones del canciller René Castro en Holanda, donde «Castro señaló la necesidad de elevar la capacidad armada de Costa Rica para defenderse de fuerzas extranjeras y protegerse del narco» (Murillo, 14 de enero de 2011, p. 5A). Ante una situación de este tipo los medios de comunicación generan miedo en la población y se alían con el Gobierno en todo un proceso de militarización, en el que las ventajas para el país son prácticamente nulas y el único beneficio visible es el de la industria armamentista, que lucraría con la venta de armas. Las suposiciones que involucren al Gobierno costarricense dentro de estos beneficios, sin embargo, no podrían ser más que especulaciones que escapan a este análisis.

\section{Militarización: un proceso oculto en Costa Rica}

La militarización es un tema delicado dentro de la investigación, hablar de procesos de militarización en un país sin ejército, al menos de manera formal, es complicado, sobre todo cuando algunos de sus habitantes consideran imposible que un proceso de estos se dé en nuestro país, sea por convencimiento o por hipocresía; al mismo tiempo que el exaltamiento del imaginario nacional se encarga de lanzar una cortina de humo sobre los verdaderos acontecimientos, ocultando la realidad por parte del Gobierno y en complicidad con algunos medios de comunicación. 
Respecto al conflicto entre los Gobiernos de Costa Rica y Nicaragua, este tema ha salido a flote y ha creado controversia; el canciller de la República René Castro declaró a radio Netherlanden Holanda que Nicaragua ha llevado a Costa Rica a considerar su tradición pacifista y puso en el tapete la necesidad de crear una fuerza similar a un ejército en Costa Rica. «Es hora de reconsiderar el pacifismo que caracteriza a Costa Rica. Es hora de armar fuerzas de seguridad que no se llamen ejército, pero que tengan capacidad de defensa contra ejércitos extranjeros en eventuales confrontaciones» (Murillo, 2011); declaraciones de este tipo, aunadas a la propuesta que hizo la presidenta Chinchilla de crear «un "impuesto para la defensa nacional" para financiar un sistema de resguardo nacional como un cuerpo especializado en las fronteras» (Murillo, 2011), han llevado a un choque de opiniones, entre las que se encuentra que esta llamada policía de fronteras es una fuerza militar y acerca a Costa Rica al militarismo.

Ahora bien, este tipo de propuestas o intensiones no podrían llevarse a cabo si la población no aprueba dichas posturas, por lo que se busca el convencimiento por medio de discursos persuasivos, muestras de inseguridad e indefensión (ejemplos: isla Calero, narcotráfico e inseguridad ciudadana) y el apoyo de los medios de sensación de necesidad de un ejército, o al menos de una fuerza militar, similar a esta figura. De esta manera, se logra que la población se identifique con las acciones del Gobierno, sobre todo en lo que respecta a su política exterior, en este caso específico, relacionado con el manejo del conflicto con Nicaragua, generando lo que se denomina como moral nacional, o sea «el grado de determinación con el que una nación apoya las políticas internacionales de su gobierno en épocas de paz o guerra» (Morguenthau, 1986, p. 171). Este apoyo popular, aunado a la declaración de un enemigo común: el Gobierno nicaragüense, especialmente Daniel Ortega -como lo declaró la presidenta Chinchilla, cuando afirmó que en enero «activará una avanzada diplomática en países de la Unión Europea, para intentar elevar la presión contra Nicaragua, a cuyo gobierno incluyo entre los "enemigos"» (Murillo, 2010, p. 6A), culmina generando la unión de la nación, en fin de un objetivo común, o, en este caso, en contra de un enemigo común.

Hasta críticos acérrimos del Gobierno le brindaron su apoyo en «defensa de la soberanía nacional», incluso fomentando el carácter bélico del discurso de Gobierno, como fue el caso de Manuel Mora, quien afirmó 
que «en estos momentos Costa Rica debe estar fuertemente unida ante la "agresión nicaragüense" para que no crean que por ser un país sin ejército "somos pendejos y maricones"» (Ramírez, 24 de noviembre, 2010, pp. 4-5), agregando que «está dispuesto a ir a reunir excombatientes con experiencia en la guerra en Nicaragua, ponerse al frente de ellos y ofrecer al gobierno de Chinchilla si fuera necesario hacer respetar la soberanía costarricense» (Ramírez, 2010, pp. 4-5). Además de los llamamientos a la unidad nacional que hizo la misma Laura Chinchilla, al proclamar que «debemos estar unidos cuando la agresión y la provocación nos ponen a prueba» (Arroyo, 4 de noviembre, 2010, p. 2); el ex presidente Abel Pacheco también afirmó que «la patria está en juego y llamó a mantener el absoluto y total apoyo a la presidenta» (Solano, 16 de noviembre, 2010, p. 2).

Pascual Serrano, citando al líder Nazi Hermann Goering (s.f.), dio una muestra de este tipo de comportamiento por parte del Gobierno:

El pueblo puede ser atraído por el mandato de los líderes. Eso es fácil. Todo lo que hay que hacer es decirles que están siendo atacados y denunciar a los pacifistas por su falta de patriotismo y por exponer al país al peligro. Funciona del mismo modo en cualquier país (2009, p. 64).

Al basarse en estas afirmaciones del líder nazi y compararlas con las declaraciones de los miembros del Gobierno se puede ver cómo realmente responden a esta necesidad de hacer sentir temerosa a la población, y más aún cuando los medios de comunicación incitan el temor y la agresión; por ejemplo, José María Tijerino dijo en una conferencia de prensa que «reforzará la presencia policial en la zona, ante la presencia nicaragüense» (Arroyo, 2010 , p. 2), generando una sensación de inseguridad y temor, principalmente en los vecinos de la frontera, que posteriormente se percataron de las intensiones, y en el caso de los habitantes del Valle Central que, al estar lejos de la zona fronteriza, asimilan como cierta la información que les es suministrada por el Gobierno y los medios de comunicación, que provocan temor e inseguridad exagerando los acontecimientos.

Además podemos aunar las declaraciones del hoy ex ministro de Seguridad: «Esa movilización de tropas es una lesión a la soberanía nacional, no puede interpretarse de otra forma» (Arroyo, 2 de Noviembre 2010, p. 2) y 
del canciller René Castro: «El canciller de la República René Castro, ratificó ayer que "Costa Rica es víctima de una invasión de militares extranjeros"» (Arroyo, 9 de Noviembre de 2010, p. 6). En el sitio de Facebook del Ministerio de Relaciones Exteriores se provoca la exacerbación del nacionalismo y la sensación de estar siendo agredidos, que despierta en algunos sus mayores deseos bélicos y de agresividad, como se vio en las declaraciones de Manuel Mora. Si a esto se suman los titulares de periódicos que provocan mayor temor, como el siguiente: «Ejército nica abre nuevo puesto junto al San Juan» (Hernández, 2010, p. 5A), el efecto en la población es aún mayor.

Y es que «además de satanizar al rebelde, fomentar el odio y legitimar guerras, los medios deben colaborar en que los ciudadanos se sientan inseguros y en peligro. Hay que despertar en el individuo la necesidad de sentirse protegido mediante métodos y cuerpos que operan con violencia» (Serrano, 2009, p. 109), tratando de «convencer a la ciudadanía de la idoneidad de que los recursos se destinen a policías y militares» (2009, p. 110), junto a llamamientos de parte del Gobierno, en este caso en voz de la Presidenta, quien «clamó a todos los sectores por buscar recursos que fortalezcan la fuerza pública» (Solano, 2 de diciembre, 2010, p. 6).

Asimismo, René Castro había dicho en sus declaraciones a radio Netherland:

Tenemos que invertir seriamente; lo que implica recursos extra sustanciales. Hicimos un estudio de lo que invierte toda América Latina y en actividades similares invierte entre el $2 \%$ y el $4 \%$ del PIB en las fuerzas que hacen este tipo de tareas. Una gran cantidad de dinero. Es lo que nuestro país invierte en universidades públicas (...) Tendremos que hacer lo mismo para actualizar nuestras fuerzas y tener equipo moderno (Murillo, 2011).

En fin, situaciones y afirmaciones de este tipo demuestran diversas intenciones de carácter militar detrás de este conflicto, se puede ver cómo los medios de comunicación juegan un papel realmente importante dentro de este conflicto, y el manejo de la información puede despertar pasiones realmente deplorables en la población. Su complicidad en el aumento de la xenofobia es palpable y su relación con los procesos de militarización deja mucho más para pensar y analizar. Los procesos de militarización son 
procesos que ocurren en todas partes del mundo, y en este caso en particular nos afecta directamente, por lo cual deberíamos analizar de manera más critica la información que nos llega, al menos no dejarnos engañar y hacer un esfuerzo, aunque sea pequeño, para mostrar y comunicar lo que consideramos como real.

\section{Bibliografía}

Aguilar, A. (16 de noviembre de 2010). Yo no tengo bandera. La Nación, pág. 31A.

Arroyo, F. (2 de noviembre de 2010). Comprueban incursión nica en territorio nacional. Al Día, pág. 2.

Arroyo, F. (9 de noviembre de 2010). Insulza no bajó en isla Calero. Al Día, pág. 6.

Arroyo, F. (12 de noviembre de 2010). Llenan de soldados la frontera. Al Día, pág. 2.

Arroyo, F. (4 de noviembre de 2010). Presidenta condena agresión en la frontera. Al Día, pág. 2.

Asamblea Legislativa de la República de Costa Rica. (01 de Septiembre de 2009). Ley General de Migración y Extranjería. San José, San José, Costa Rica.

Cambronero, N. (18 y 19 de diciembre de 2010). Laura arremete contra Ortega. La República, pág. 4.

Castro, R. (2011). Radio Netherland Wereldomroep LATINOAMÉRICA. Recuperado de http:// www.rnw.nl/espanol/article/entrevista-a-rene-castro-ministro-de-rree-de-costa-rica.

Dussel, E. (1998). Ética de la liberación en la edad de la globalización y la exclusión. Madrid, España: Editorial Trotta.

Editorial de La Nación (6 de noviembre de 2010). La visita de Insulza. La Nación, pág. 32A.

Editorial de La Nación (16 de noviembre de 2010). Avance en la OEA. La Nación, pág. 29A.

Editorial de La Nación (9 de diciembre de 2010). Después de la OEA. La Nación, pág. 34A.

Editorial de La Republica (20 y 21 de noviembre de 2010). Solución Urgente: OEA + ONU. La República, pág. 14.

Foucault, M. (1998). Genealogía del Racismo. La Plata, Agentina: Editorial Altamira.

González, B. (1 y 2 de 2011). Proyecto Calero: una historia de militarización y xenofobia [documental]. (E. Aguilar Ramírez y E. Llaguno Thomas, entrevistadores).

Hernández, C. (21 de noviembre de 2010). Ejército nica abre nuevo puesto junto al San Juan. La Nación, pág. 5A.

Marquez Rodríguez, A. (06 de Marzo de 2005). WebArticulista.Net. Recuperado el 30 de Mayo de 2011, de WebArticulista.Net: http://webarticulista.net.free.fr/sobarania. html\#top

Mora, M. A. (2007). Los monstruos y la alteridad. Escuela de Filosofía, Universidad Nacional. Heredia, Costa Rica.

Morguenthau, H. (1986). Política entre las naciones: la lucha por el poder y la paz. Buenos Aires, Argentina: Grupo Editor Latinoamericano.

Murillo, G. (s.f.). www.iidh.ed.cr. Recuperado de http://www.iidh.ed.cr/comunidades/ redelectoral/docs/red_diccionario/soberania.htm 
Murillo, A. (9 de diciembre de 2010). Superada la OEA, Gobierno esperará decisión de La Haya. La Nación, pág. 6A.

Murillo, A. (12 de enero de 2011). Canciller Castro ve necesario reconsiderar tradición pacifista. Recuperado de http://www.nacion.com/2011-01-13/ElPais/NotasSecundarias/ ElPais2649848.aspx?Page $=3$

Murillo, A. (14 de enero de 2011a). Jueces de la Haya piden a Managua aclarar dudas. La Nación, pág. 5A.

Murillo, A. (14 de enero de 2011b). Unidad especial ya se entrena para defender fronteras. La Nación, pág. 5A.

Oviedo, E. (26 de noviembre de 2010). Confianza en ejecutivo cae en primer trimestre. La Nación, pág. 5A.

París, L. (20 de Enero de 2011). Vestigio del espíritu militar. La Nación , pág. 28A.

Pla, I. L. (Octubre-noviembre de 2001). Medios de comunicación y democracia: realidad, cultura cívica y respuestas legales y políticas. Razón y palabra, No. 23. Recuperado de http://www.razonypalabra.org.mx/anteriores/n23/23_iluna.html

Ramírez, E. (24 de Noviembre de 2010). Pasividad de Estados Unidos es preocupante en conflicto, advierte experto militar. Semanario Universidad, págs. 4-5.

Rodríguez, L. (2006). El concepto de nación y la fundamentación del nacionalismo. Recuperado de www.omegalfa.es/downloadfile.php?file=libros/el-concepto-de-nacion.

Sandoval, C. (2002). El «otro» nicaragüense en el imaginario colectivo costarricense. Algunos retos analíticos y políticos. Coloquio Panamericano: Industrias Culturales y Diálogo de las Civilizaciones en las Américas. Montreal, Canadá.

Serrano, P. (2009). Medios violentos: palabras e imágenes para el odio y la guerra. La Habana, Cuba: Editorial José Martí.

Silva, J. A. (8 de noviembre de 2010). Xenofobia desatada en Costa Rica. Recuperado de http://www.elnuevodiario.com.ni/nacionales/87528-xenofobia-desatada-costa-rica/

Solano, H. (14 de noviembre de 2010). Invasión roba tranquilidad a isla más grande de la región. Al Día, pág. 2.

Solano, H. (16 de noviembre de 2010). Daniel Ortega condiciona el retiro de tropas de isla Calero. Al Día, pág. 2.

Solano, H. (1 de diciembre de 2010). Mayoría aprueba labor de Chinchilla. Al Día, pág.6

Solano, H. (2 de diciembre de 2010). Chinchilla endurece el tono contra Ortega. Al Día, pág. 6.

Solís, P. J. (2009). El fenómeno de la xenofobia en Costa Rica desde una perspectiva histórica. Revista de Filosofía de la Universidad de Costa Rica, 28, 91-97.

Sorj, B. (2010). Poder político y medios de comunicación: de la representación política al reality show. Buenos Aires, Argentina: Siglo XXI Editores.

Von Clausewitz, K. (2003). De la guerra. Buenos Aires, Argentina: Editorial Astri.

Zanella Figueroa, H. (2007). La influencia de los medios de comunicación en el desarrollo político del país. Recuperado de http://www.universidadabierta.edu.mx/Biblio/Z/Zanella\%20 HectorMedios\%20comunicacion.htm 